\title{
O PAPEL DA COLÔNIA DE PESCADORES NA CIDADE DE BABAÇULÂNDIA (TO): O TRABALHO E VIDA DAS COMUNIDADES RIBEIRINHAS
}

The role of the fishermen colony in Babaçulândia City (TO): the work and lifestyle of the riverside communities

El papel de la colonia de pescadores en la ciudad de Babaçulândia (TO): el trabajo y vida de las comunidades ribereñas

\section{Delismar Palmeira Costa ${ }^{* 1}$, Alberto Pereira Lopes ${ }^{2}$}

${ }^{1}$ Graduado em Geografia pela Universidade Federal do Tocantins - UFT Araguaína/TO. E-mail: delismarcosta@gmail.com

${ }^{2}$ Doutor em Geografia Humana (USP) e Professor do Curso de Geografia - UFT, Araguaína/TO. E-mail: beto@mail.uft.edu.br

*Correspondência: Grupo de Estudos Agrários e Direitos Humanos (GEADH), Av. Paraguai, s/n - Setor Cimba, Araguaína - TO, CEP: 77824-838 E-mail: beto@mail.uft.edu.br

\section{Artigo recebido em 30/10/2015. Aprovado em 09/12/2015. Publicado em 24/02/2017.}

\section{RESUMO}

Nesse trabalho buscou-se analisar a importância da colônia de pescadores da cidade de Babaçulândia (TO), por meio da investigação das atribuições que lhes são delegadas no manejo do pescado e na representação dos ribeirinhos associados perante as instâncias jurídicas nas lutas pela garantia de seus direitos. Assim, foi apurado um número de duzentas famílias associadas, que estão sob a jurisdição e proteção da colônia em debate. O trabalho também contemplou e analisou os prejuízos causados pela construção da Usina Hidrelétrica de Estreito na vida cotidiana dos ribeirinhos, tais como a diminuição do pescado, o processo de desterritorialização e as indenizações injustas. Para atingir esses objetivos foram feitas visitas a campo e a aplicação de entrevistas a membros associados, bem como também aos dirigentes da colônia, totalizando um quantitativo de dez entrevistas, que tiveram por fim assimilar a forma de organização da mesma, e verificar como os ribeirinhos veem e sentem os problemas trazidos após a construção da hidrelétrica nas suas relações sociais, econômicas, culturais e com o meio físico.

Palavras-chave: Colônia. Hidrelétrica. Ribeirinhos.

\section{ABSTRACT}

The present work aimed to analyze the importance of the fishermen colony from the city of Babaçulandia (TO) through the investigation of the assignments, which are delegated to them in the fish handling and the representation of the associated Ribeirinhos before the legal entities in the struggles to guarantee their rights. Thus, a number of two hundred associated families were found, which are under the jurisdiction and protection of the colony under debate. The work also contemplated and analyzed the damages caused by the construction of the Estreito Hydroelectric Power Plant in the everyday life of the Ribeirinhos, such as the reduction of fish, the process of deterritorialization and unjust compensation. In order to achieve these objectives, field visits and interviews with associate members were carried out, as well with the leaders of the colony, totalizing a quantitative of ten interviews, whose purpose was to assimilate the way of organization of that community, and to verify how the Ribeirinhos perceive and feel the problems brought after the construction of the hydroelectric plant in their social, economic, cultural and physical environment.

Keywords: Colony. Hydroelectric. Ribeirinhos. 


\section{RESUMEN}

En ese trabajo buscó analizarse la importancia de la colonia de pescadores de la ciudad de Babaçulândia (TO), por medio de la investigación de las atribuciones que les son delegadas en el manejo del pescado y en la representación de los ribereños asociados ante los ejemplares jurídicos en las luchas por la garantía de sus derechos. Así, fue filtrado un número de doscientas familias asociadas, que están bajo la jurisdicción y protección de la colonia en debate. El trabajo también contempló y analizó los perjuicios causados por la construcción de la Fábrica Hidroeléctrica de Estreito en la vida cotidiana de los ribereños, tales como la disminución del pescado, el proceso de desterritorialización y las indemnizaciones injustas. Para alcanzar esos objetivos fueron hechas visitas a campo y la aplicación de entrevistas a miembros asociados, así como también a los dirigentes de la colonia, totalizando un cuantitativo de diez entrevistas que tuvieron por fin asimilar la forma de organización de la misma, y verificar como los ribereños ven y sienten los problemas traídos después de la construcción de la hidroeléctrica en sus relaciones sociales, económicas, culturales y con el medio físico.

Descriptores: Colonia. Hidroeléctrica. Ribereños.

\section{INTRODUÇÃO}

A política energética brasileira tem sido alvo de muitas críticas em relação à sua prática (des) estruturadora tanto em aspectos ambientais como sociais. Pautada principalmente na construção de usinas hidrelétricas, tal política tem se caracterizado principalmente pelos seus graves impactos à natureza e também pelos malefícios causados com desterritorialização das comunidades tradicionais.

No meio-técnico-científico-informacional em que vivemos ou simplesmente a égide da globalização, cada lugar passa a ter importância nas etapas que garantem a sobrevivência do modo de produção capitalista, de modo que os lugares tornamse alvos de investimentos que visam a maior difusão do capital, sendo agora os espaços escolhidos e racionalizados pela lógica capitalista de acordo com as suas vocações específicas, segundo Santos (2006); estas por sua vez podem ser de ordem natural como foi o caso da região onde fora implantada UHEEstreito.

Sendo assim, "O econômico e o político pressionam o social, o que equivale a avaliar o empobrecimento da vida social, no sentido dela se dobrar à vida privada, num mundo tecnológico e economicamente desenvolvido" (DAMIANI, 2002, p. 163). Isto é o que acontece em locais onde são implantadas as usinas hidrelétricas, uma vez que o remanejo dos ribeirinhos acaba por separá-los do meio onde sempre viveram ou mesmo uns dos outros, perdendo-se os elos de vizinhança, e configurando, deste modo, o processo de desterritorialização.

Nesse trabalho buscou-se analisar a importância da colônia de pescadores da cidade de Babaçulândia (TO) e os impactos causados aos ribeirinhos após a construção da Usina Hidrelétrica de Estreito.

O texto se divide em quatro tópicos além desta introdução, são eles: materiais e métodos, onde são explicados os meios e bases bibliográficas que foram necessários para que a pesquisa fosse feita; nos resultados e discussões, procuramos demonstrar os objetivos que foram alcançados pela pesquisa e suas problemáticas; a conclusão também faz parte do texto; e por ultimo a literatura citada, que foram também o norte no desenvolvimento desse trabalho.

\section{MATERIAIS E MÉTODOS}

Foram feitas leituras que buscassem mostrar a importância da vida cotidiana tradicional e como o 
modo capitalista de produção acaba por findá-las, isso fora possível pela consulta de autores que trabalham tanto o modo de produção quanto a questão do cotidiano em si, a leitura de monografias locais e os periódicos relacionados à questão das hidrelétricas também fora de suma importância. Assim, trabalhou-se com autores: Santos (2006), Damiani (2002), Santos; Sieben (2014), Haesbaert (2006), Silva; Machado (2013), Santos; Chaves (2013), Rezende (2014).

A pesquisa contou também com uma visita a campo para a realização de entrevistas, por meio de um roteiro construído com questões abertas e fechadas. Foram realizadas treze entrevistas com membros e dirigentes da colônia. Desse modo, podemos dizer que elas foram de grande valia no andamento da análise, pois possibilitaram um maior esclarecimento acerca das questões em debate. Não se trata de um método totalmente empírico, mas de uma busca por resultados que perpassa pela sua utilização, mesmo que de forma parcial.

\section{RESULTADOS E DISCUSSÃO}

\section{- A importância Colônia de Pescadores}

De um modo geral as colônias de pescadores desenvolvem um papel significante na produção do espaço; ou conforme Resende (2014), que afirma a importância das mesmas, pois foram de fundamental importância para assegurar o domínio do territorial brasileiro durante o início do século XX. Assim, pode-se notar que acima de tudo as colônias de pescadores são um instrumento institucional que contribuem de certa forma para o andamento da economia nacional.

A colônia de pescadores de Babaçulândia (TO) tem um papel de grande relevância no que diz respeito à comercialização do pescado e à organização dos ribeirinhos. A presidente da colônia ressaltou a funcionalidade da mesma no que diz respeito à asseguração dos direitos dos associados, tais como a garantia do seguro defeso e a representação perante os órgãos de fiscalização e reguladores.

Imagem 1. Colônia de Pescadores de Babaçulândia-TO

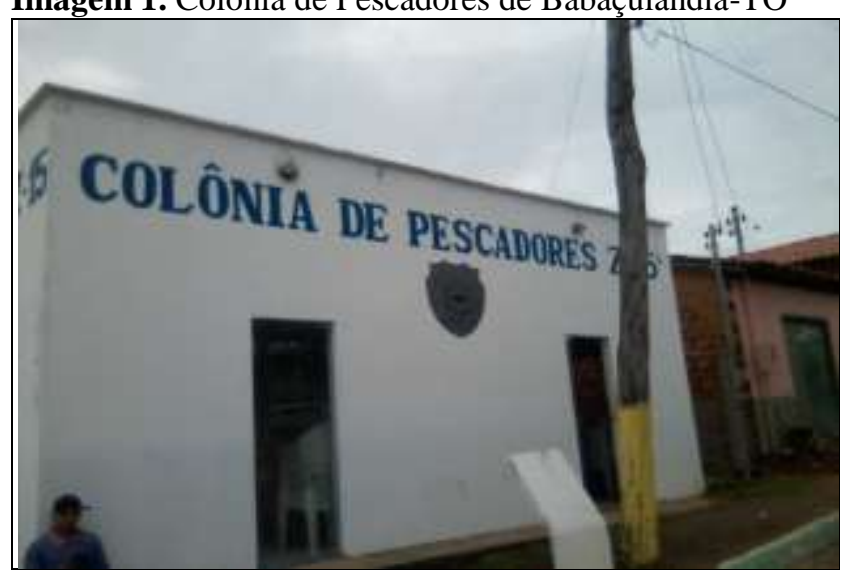

Fonte: Delismar Palmeira Costa (ago, 2014).

O local da pesquisa está situado no município de Babaçulândia (TO), a colônia foi criada em 20 de março de 2004, é mantida com a cooperação dos pescadores do município, tendo também subsídios técnicos e financeiros advindos de programas como o PRONAF (Programa Nacional de Fortalecimento da Agricultura Familiar) e de instituições como RUARALTINS (Instituto de Desenvolvimento Rural do Tocantins) e RURALNORTE (Rural Norte Empresa de Desenvolvimento Rural Ltda).

Do ponto de vista econômico a colônia facilita a vida dos pescadores, pois ela negocia o pescado em melhores condições, aumentando assim a rentabilidade. Caso não houvesse a sua mediação os pescadores seriam possivelmente explorados em relação aos preços de seus pescados.

\section{- A diminuição do pescado}

Através da pesquisa realizada pôde-se notar pelas entrevistas e dados coletados que houve uma diminuição significativa do volume de pescado, sobretudo após construção da usina hidrelétrica. Isso se deve muito ao fato de que o represamento da água influencia no seu processo de desoxidação, facilitando a proliferação de fitoplantas maléficas à fauna aquática. 
$\mathrm{Na}$ fala da presidente da colônia de pescadores, Josefa Almeida, em uma entrevista concedida é possível notar como era a abundância de peixes antes da construção da barragem:

\begin{abstract}
"Antes nós conseguíamos oito centos quilos de peixes, antes tinham os cardumes, você está entendendo? Tinham os cardumes que você ia e pescava meu Deus do céu! Hoje você não pega.[...]. O filho da Maria Monteiro mesmo, o Júlio, ele era um dos pescadores que mais pescava peixes aqui na região, então a produção de pescado ela caiu, caiu demais, sem dizer que morreu oitenta toneladas de peixes abaixo da barragem não é, e isso é prejuízo para quem?" (J. A., entrevista em 20/01/2015).
\end{abstract}

Imagem 2. Mortandade de peixes

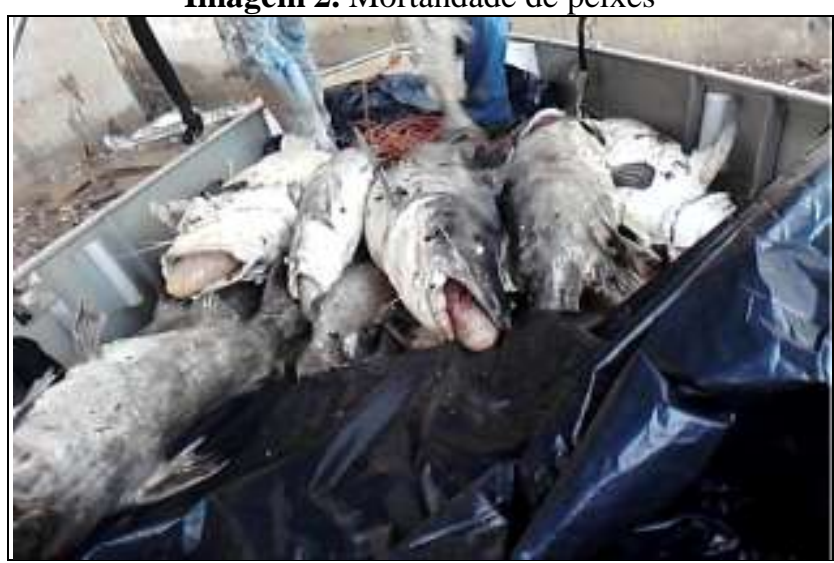

Fonte: Colônia de Pescadores de Babaçulândia-TO (2013)

Essa diminuição do pescado ocorre em virtude da "[...] contaminação da água. Isso acontece porque, quando se interrompe o percurso normal de um rio, mudanças na qualidade da água são verificadas em sua composição química, física e térmica" (SILVA; MACHADO, 2013, p. 223). Tudo isso contribui para a mortandade de peixes, e assim também para decadência econômica dos que dependem da pesca para sobreviver.

\section{- O processo de desterritorialização}

A UHE Estreito também produziu um processo caótico de desterritorialização, pois remanejou-se forçadamente os grupos que ali viviam para outras regiões, um bom exemplo é do assentamento "Mirindiba" localizado em Araguaína (TO) destinado à abrigar as pessoas que antes residiam às margens do rio Tocantins na Ilha de São José, segundo Santos; Sieben (2014). Tal processo se deu automaticamente com uma reterritorialização, pois como nos assevera Haesbaert (2006), não há desterritorialização se uma reterritorialização seguida. O novo lugar será, mesmo que forçadamente, o seu novo território.

Muitos dos atingidos receberam uma carta de crédito no valor de quarenta e cinco mil reais para comprarem uma casa já construída em outro local, enquanto outras famílias foram remanejadas para um assentamento urbano localizado em Babaçulândia chamado "Novo Milênio".

Imagem 3. Reassentamento Novo Milênio

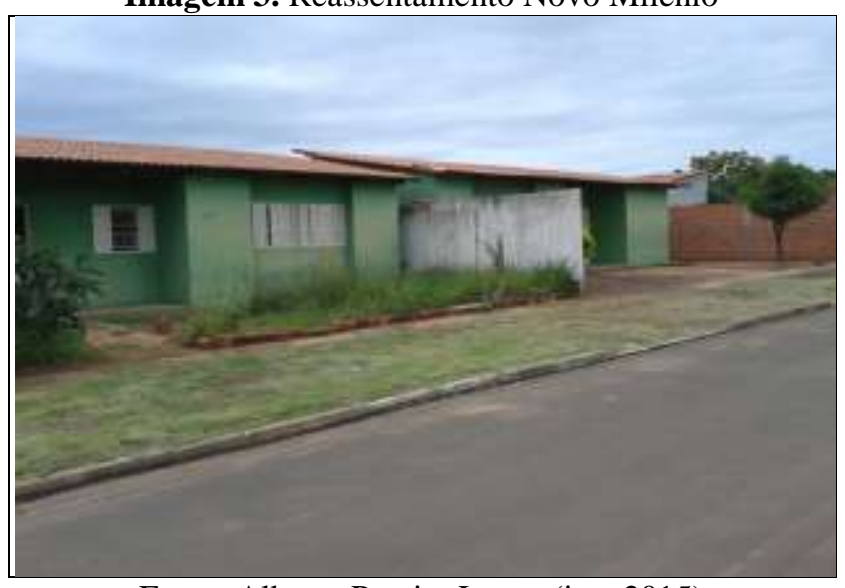

Fonte: Alberto Pereira Lopes (jan. 2015)

Segundo alguns relatos em entrevistas o lugar é muito conturbado, sobretudo pelo fato de ter sido construído sobre um lençol freático que danifica as estruturas das casas. Outro aspecto diz respeito à incompatibilidade dos novos locais em relação aos antigos, sendo os últimos bem maiores e produtivos que os atuais. As novas moradias são totalmente desestruturadas e inseguras para a habitação, o que mostra a falta de fiscalização dos órgãos competentes e a inexistência de um amparo jurídico aos ribeirinhos desterritorializados.

Imagem 4. Falta de estrutura nas novas moradias 


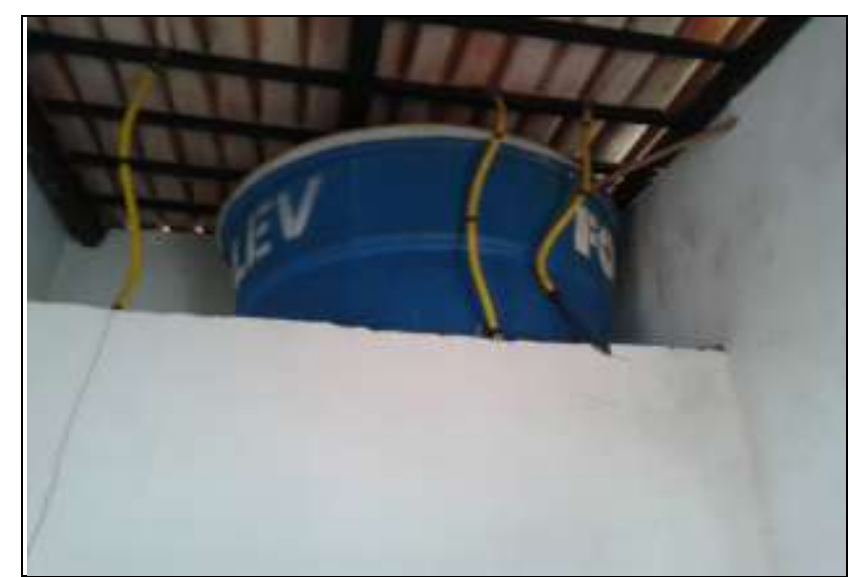

Fonte: Alberto Pereira Lopes (jan. 2015)

O passado é deixado para traz de uma forma forçada em todos os aspectos da vida social, uma vez que, “[...] o território pode ser concebido a partir da imbricação de múltiplas relações de poder, do poder mais material das relações econômico-políticas ao poder mais simbólico das relações mais estritamente cultural" (HAESBAERT, 2006, p. 79). Todos estes componentes da territorialidade são tirados dos ribeirinhos, sendo imposta a eles uma nova territorialidade, forçada e não satisfatória.

O que passa a vigorar a parti de então é uma sensação de impotência entre os atingidos, pois como nos fala Santos; Chaves (2013), “desterritorialização significa a perda do poder de autorreprodução de suas formas de organização política-econômica-cultural, ou seja, perda do poder de exercer ação/transformação sobre o território" (p. 197). As atividades antes exercidas pelos atingidos são interrompidas, ou melhor, extintas, o que gera uma sensação de impotência e insegurança em ralação aos seus futuros.

Os danos causados aos impactados são imensuráveis no que diz respeitos às suas relações mais simbólicas com o entorno e de vizinhança, já que, "quando o atingido é obrigado a deixar sua fração territorial, ou seja, lugar onde sempre exerceu o seu modo de vida e produziu suas condições sociais de produção, ele sofre pela perda de sua identidade cultural" (SANTOS; CHAVES, 2013, p.197).

\section{CONCLUSÃO}

Por meio destes apontamentos buscou-se mostrar como a política energética brasileira tem interferido na atividade pesqueira no município de Babaçulândia. Foi discutida a importância econômica e social da colônia de pescadores e qual a sua influência na vida dos pescadores no que diz respeito à organização econômica, cultural e cotidiana de um modo geral.

A mortandade dos peixes e a perda de elos culturais foram aspectos contemplados nessa pesquisa, os arranjos físicos do lugar influenciam diretamente no comportamento das pessoas no seu cotidiano. A desterritorialização rompeu com tudo isto e impôs aos ribeirinhos novos modos de vida que lhes são estranhos, isso cria dentro das pessoas o sentimento de nostalgia e um entristecimento pela atual situação.

O processo de desapropriação dos moradores, que debatemos, foi um procedimento de extrema injustiça, sobretudo pelos valores atribuídos aos antigos terrenos que margeavam o rio Tocantins em Babaçulândia antes da construção da barragem. Isso serve de base para a conclusão de que houve um processo de desterritorialização forçada, e acima de tudo institucional, pois contou com o aval e interesse do Estado brasileiro.

Pode-se dizer que os ribeirinhos foram os maiores lesados com a implantação deste empreendimento, e em outro plano toda a população da cidade, uma vez que o modo de vida ali préexistente fora escamoteado por atores hegemônicos, destruindo as estruturas econômica, cultural e social anteriores ao enchimento do lago. Gerando para a sociedade ribeirinha uma sensação de impotências frente à reprodução hegemônica do capital. 
Todos os autores declararam não haver qualquer potencial conflito de interesses referente a este artigo.

\section{REFERÊNCIAS}

DAMIANI, Amélia. O lugar e produção do cotidiano. In: CARLOS, Ana Fani. (Org). Novos Caminhos da Geografia. São Paulo: Contexto, 2002.

HAESBAERT, Rogério. O mito da desterritorialização: do "fim dos territórios" à multiterritorialidade. Rio de Janeiro: Bertrand Brasil, 2006.

RESENDE, Alberto. A origem da institucionalidade da pesca artesanal. In: SILVA, Catia. (Org). Pesca artesanal e produção do espaço: desafios para reflexões geográficas. Rio de Janeiro: Consequência, 2014.

SANTOS, Alisson; SIEBEN, Airton. Hidreletricidade e des-re-territorialização: uma análise a partir no reassentamento Mirindiba localizado no município de Araguaína-TO. Revista Tocantinense de Geografia. Araguaína, n. 01, p. 1-10, 2014.

SANTOS, Milton. A Natureza do Espaço: técnica e tempo, razão e emoção. São Paulo: Editora da Universidade de São Paulo, 2006. (Coleção Milton Santos; 1).

SANTOS, Viviane; CHAVES, Patrícia. Conflitos territoriais entre atingidos por barragens e atuação do Estado em Carolina-MA. In: BRITO, Eliseu Pereira de. Recortes geográficos sobre Araguaína e outros lugares. São Paulo: Schoba, 2013.

SILVA, Marcela; MACHADO, Carlos. Do rio ao lago: uma abordagem sobre os impactos socioambientais a partir da construção da UHEEstreito para o município de Carolina-MA. In: BRITO, Eliseu Pereira de. Recortes geográficos sobre Araguaína e outros lugares. São Paulo: Schoba, 2013. 